\title{
QUALITY PAPER Quality objectives in management systems - their attributes, establishment and motivational function
}

Quality objectives in management systems

Received 26 May 2020 Revised 13 October 2020 5 January 2021 Accepted 26 January 2021

\author{
Department of Quality Management, Uniwersytet Jagiellonski w Krakowie, \\ Cracow, Poland, and \\ Piotr Jedynak \\ Jagiellonian University in Krakow, Krakow, Poland
}

Marek Bugdol ${ }^{\bullet}$

\begin{abstract}
Purpose - The aim of this paper is to show the ways of setting quality objectives, their attributes and the conditions under which they can perform a motivational function.

Design/methodology/approach - Collecting relevant data, the authors used the results of previous research and theoretical assumptions concerning quality objectives. Subsequently, they carried out a survey and exemplification research based on participatory observations, document content analysis and interviews.

Findings - Goals are set mainly by top management, but the communication process itself is insufficient; the needs of system users are not taken into account. In the opinion of the employees, quality objectives are measurable and objective, although not very ambitious. For quality objectives to fulfil a motivational function, they should be objective and measurable. Also, the allocation of tasks among employees needs to be fair. Furthermore, quality objectives have to play a greater role in remuneration systems.

Originality/value - This paper is one of the first publications on the role and function of quality objectives. Its advantage is that it defines the conditions under which such objectives can have a motivational effect and encourage employees to pursue the improvement of their products and services.
\end{abstract}

Keywords Quality objectives, ISO 9001, Motivation, Quality improvement

Paper type Research paper

\section{Introduction}

The aim of this paper is to show the ways of setting quality objectives, their attributes and conditions under which they can fulfil a motivational function.

The topic is important because quality objectives determine the directions of undertaken improvement activities and allow organizations to measure the effectiveness of their quality management systems. However, the previous literature concerning quality objectives has not been too extensive. So far attempts have been made to define quality objectives (ISO 9000:2015, Quality Management Systems - Fundamentals and Vocabulary, Price, 2002), the methods of setting quality objectives have been described (Djouab et al., 2016; Bexelius et al., 2018; Zapłata, 2018; Tadic et al., 2013; Martínez-Moreno and Díaz Suárez, 2016), their importance has been emphasized (Deming, 2012; Dale, 1999), the attributes of quality

(C) Marek Bugdol and Piotr Jedynak. Published by Emerald Publishing Limited. This article is published under the Creative Commons Attribution (CC BY 4.0) licence. Anyone may reproduce, distribute, translate and create derivative works of this article (for both commercial and non-commercial purposes), subject to full attribution to the original publication and authors. The full terms of this licence may be seen at http://creativecommons.org/licences/by/4.0/legalcode

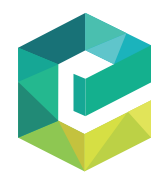

International Journal of Quality \& Reliability Management Vol. 39 No. 1,2022

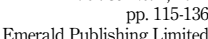
Emerald Publishing Limited DOI 10.1108/IJQRM-05-2020-0173 
IJQRM

39,1

objectives and the conditions of their functioning have been identified (Hirzalla et al., 2014; Oakland, 1995; Bugdol, 2018; Zapłata, 2018; Tadic et al., 2013; Allison and Byron, 1996; Djouab et al., 2016; Tadic et al., 2013) and problems with their setting and achievement have been highlighted (Tadic et al., 2013; Deming, 2012; Carson and Carson, 1993). Few publications indicate the function motivating employees to pursue quality objectives (Shackleton and Wale, 2002; Whitaker and Levy, 2012; Gilliland and Landis, 1992; Locke, 1978; Huczynski and Buchanan, 1991; Fishbach, 2018).

The conducted literature review has shown that little is known about the level of awareness of quality objectives in organizations with a quality management system in place, about people who factually set quality objectives, and whether they are imposed or established in cooperation with all interested parties. This is important as the process may identify existing management styles and even the level of trust in employees (these issues, however, require other further research). We are interested in employees' opinions on the attributes of quality objectives: to what extent they are measurable and objective and whether they are related to strategic objectives (as indicated in the requirements of ISO 9001).

Prior to the research, various theories of objectives were reviewed, e.g. the theory of goal attainment, the theory of management by objective or the theories of motivation proposed, among others, by Locke or Vroom. There are indeed studies on the motivational function of objectives, which we also cite. In most cases, however, they do not refer to quality objectives but to other types of goals such as educational, financial or personal. The motivational function of quality objectives has been the object of research conducted, among others, by Oakland (1995), but even his observations relate to the psychological theories formulated by Hackman and Oldham.

We were interested in the extent to which quality objectives were taken into account in financial motivation systems, and more specifically in top management remuneration systems. Our focus was on the significance of achieving quality objectives in awarding bonuses to employees, the degree to which bonus awarding was based on a system of adopted rules consistent with procedural justice, employees' opinions on the fairness of the allocation of tasks among them and the identification of factors motivating people to improve quality.

It is very important as rewarding people for achieving quality objectives is a contentious issue. In general, it is believed that quality improvement should be something natural that does not have to be supported with financial rewards (Dale, 2001). Deming was against commissionbased remuneration, but he criticized mainly financial objectives (Deming, 2012). According to Crosby, if work is designed improperly, such a motivational system breeds errors (Crosby, 1979). Motivation based on a financial system was also rejected by Ishikawa (1985). On the one hand, organizations reward employees for the achievement of quality goals (cf. Daniel et al., 2014), but on the other hand, it has been known for a long time that solutions of this type are not compatible with the interest of an organization (Blikle, 2009), and an objective assessment of individual efforts made in pursuit of such goals is very difficult (Evan, 1992).

The paper is divided into the following parts: abstract, introduction, literature review, research methodology or approach, findings, conclusion, limitations and further research.

We decided to research this subject and present our findings because, as practising quality system auditors and also academics, we felt a deficit of knowledge of quality objectives (at the time of data collection, there was not a single article in the popular EBSCO database referring directly to quality objectives). Obviously, we are fully aware that in such a short paper, it is impossible to exhaust the subject, address all questions, and resolve doubts.

\section{Quality objectives in the literature on the subject}

In the first part of the paper, which is based on a literature review, we discuss the concept of quality objectives, their assumed attributes, problems related to their pursuit and their motivational role. 


\subsection{The understanding of quality objectives}

According to the ISO 9000 standard (paragraph 3.7.2), a quality objective is "an objective related to quality" (ISO 9000:2015, Quality Management Systems - Fundamentals and Vocabulary, p. 25). Quality objectives refer to all those tasks that not only aim to improve the quality of a product but also the quality of services and even the quality of life in the workplace. According to Dahlgaard (Rogala, 2019), the defining of quality is changing. Nowadays we refer to the quality of processes, people, partnership or influence on society. Therefore, what needs to be searched for constantly is new quality objectives that are related not only to products or services.

Quality objectives may relate not only to individual processes (and in this sense, an objective may be to reduce process variability or the number of failures) but also refer to quality maintenance and assurance. Thus, product quality is something that fulfils the intended purpose (Price, 2002).

The notion of "quality objective" is used by not only academics dealing with management sciences (Deming, 2012; Oakland, 1995; Dale, 1999; Price, 2002) but also those specializing in medicine and ecology (cf. Van Meter et al., 2018; Wysham et al., 2018). In medicine, quality objectives - in this case, treatment objectives - are defined by means of so-called "required indexes" (e.g. body weight loss, body weight index [BMI] and systolic blood pressure) (Wysham et al., 2018).

\subsection{Attributes of quality objectives}

Pointing out the characteristics of quality objectives, the authors rightly note that they are to be ambitious, aggressive (preferably related to benchmarking analysis) and specific (Hirzalla et al., 2014; Oakland, 1995). According to the ISO 9000:2015 standard, quality objectives can be set for particular processes or functions on the basis of a quality policy (ISO 9000:2015, Quality Management Systems - Fundamentals and Vocabulary, p. 25). Furthermore, quality objectives are to take into account the applicable requirements, relate to the compliance of products and services with regulations and increase customer satisfaction. They should be monitored, communicated and updated, if necessary (9000:2015, Quality Management Systems - Requirements, p. 14).

As it has already been stated, quality objectives must be measurable. Measurability depends on the availability of proper tools ensuring the most objective measurements. Measurability may also consist in determining whether something has been done or not (socalled $0-1$ objectives). An assessment of the achievement of quality objectives is the basic tool used to determine the effectiveness of a quality management system (Bugdol, 2018). Furthermore, quality objectives should be clearly defined, fully adjusted to the specificity and scope of an organization's activities and assigned to tasks to be carried out by particular individual organizational units (Zapłata, 2018). It is also recognized that quality objectives have to be linked to product requirements as well as business and strategic goals (Allison and Byron, 1996; Djouab et al., 2016). The aforementioned requirements in relation to quality objectives can be supplemented with methodological recommendations resulting from the good practices of management by objectives. According to this approach, quality objectives should be additionally (Jedynak, 2007): clear and accurate, realistic, with an incentive function, analysable by means of deviation analysis, regularly adjusted, mutually consistent and unambiguously assigned to their pursuers.

\subsection{Problems with setting quality objectives}

A number of indexes can be taken into account in setting and evaluating quality objectives, for example: the measure of process variation, the duration of the fulfilment of a production order, the level of supplies in production operations, the level of utilized production capacities,

\section{Quality objectives in management systems}


IJQRM

39,1

118

process capacity, process efficiency, reported improvement actions, savings resulting from process improvement and complaints concerning production operations (Tadic et al., 2013). Quality objectives are defined by customers, system users and other stakeholders (Djouab et al., 2016; Bexelius et al., 2018), as well as top management (Zapłata, 2018). Quality objectives can also be set on the basis of self-assessment, although this approach has not been described in detail in the literature on the subject (Martínez-Moreno and Díaz, 2016). Quality objectives regarding safety, business efficiency, ease of maintenance, etc. are often achieved by implementing the best practices (Hirzalla et al., 2014). The creators of the ISO 9004:2009 standard (ISO 9004:2009, Managing for the sustained success of an organization - A quality management approach) focused on recommendations as to what should be taken into account when setting quality objectives and indicated the following: current and future needs of the organization and its markets, appropriate arrangements from management reviews, current parameters applicable to products and processes, satisfaction levels of interested parties, self-assessment results, benchmarking results, competitiveness analysis, opportunities for improvement and resources necessary to meet the set objectives. In the new edition of this standard, (ISO 9004:2018, Quality management - Quality of an organization - Guidance to achieve sustained success) establishing and maintaining objectives is regarded as a way to fulfil the leadership function. In addition, the authors of the standard recommend that the establishment of objectives (ISO 9004:2018, Quality management - Quality of an organization - Guidance to achieve sustained success) should be carried out in a participatory manner (taking into account the interests of all stakeholders) and with respect for the principles of social responsibility. It is recognized that setting quality objectives is a difficult task, especially when dealing with changeable processes or the changing business environment (Tadic et al., 2013). The main problem is that quality objectives are described by a number of attributes and quality itself is inherently subjective, as it is highly dependent on human cognition (Tadic et al., 2013). One of the problems is not only the proper integration of quality and strategic objectives, which is emphasized in the ISO 9001:2015 standard but also the appropriate relationship between quality objectives and financial objectives. In practice, a ranking of quality objectives is carried out according to the experience of quality managers (Tadic et al., 2013).

\subsection{Motivational function of quality objectives}

The existing definitions of leadership indicate the need to set objectives and influence the behaviour of employees, including their motivation (Shackleton and Wale, 2002). It is emphasized that quality objectives are to fulfil both motivating and integrating roles (Bugdol, 2014) and are meant to improve processes and set directions for continuous improvement (Varela and Pacheco, 2018). Correctly formulated quality objectives can trigger a motivational effect. Employees perceive greater value in obtaining work-related information because it contributes to a higher level of work efficiency (Whitaker and Levy, 2012). It should be remembered that some theories of motivation refer to the goals of an organization. For example, Vroom's theory assumes that achieving first level results may increase the likelihood of success in the case of second level results. On the other hand, according to Locke's theory, difficult and specific goals can lead to higher performance (Foster, 2003). The effect of the better achievement of goals slightly exceeding skills is more easily observable when easier and not necessarily complex tasks are being carried out (what counts is the speed and accuracy of task performance) (Gilliland and Landis, 1992).

Examining the motivational function of quality objectives, it is possible to take into account various theories, focus on external or internal motivations or deal exclusively with the aspects of financial motivation, which is the case in this paper.

Writing about the motivational function of quality objectives, it should be noted that the amount of remuneration may depend on the accomplishment of quality objectives. Public 
recognition of employees for their contribution to achieving quality objectives is very popular among TQM companies (Wruck and Jensen, 1998). It is often very optimistically assumed that the amount of remuneration should depend on the achievement of quality objectives (Evan, 1992). In some organisations remuneration systems are linked to quality objectives as well as strategic objectives (Daniel et al., 2014). Invey (1992) studied the issue of employee compensation for performance in the TQM environment. His research showed that the main problem in rewarding employees for quality was to transform quality objectives into measurable targets allowing for reliable and objective assessment of individual efforts (Ivey, 1992). In many cases, the problem of rewarding employees for quality is a lack of tools to measure quality (Madhusree and David, 2006). The same can be said about making a bonus dependent on customer satisfaction (Ceniceros, 2001). This is why ideas to pay employees for quality and final results are difficult to implement, for example in the case of teachers (Mendes, 2010). It is not clear what is the quality of so-called inputs to this process, i.e. what contributes to the final result. It is not always possible to determine the measurable features of a tested quality. Criticism of rewarding employees for achieving quality objectives is based on the assumption that employees motivated by objectives do not try to work well, but instead focus on achieving objectives at any cost, which in the long run is not consistent with the interest of their employer. As it has already been noted, opinions on whether various types of objectives should be taken into consideration in remuneration systems are divided. In general, it is believed that quality improvement should be something natural that does not have to be supported with financial rewards (Dale, 2001). On the one hand, organizations reward employees for the achievement of quality goals (Wruck and Jensen, 1998; Daniel et al., 2014), but on the other hand, it has been known for a long time that solutions of this type are not compatible with the interest of an organization (Blikle, 2009) and an objective assessment of individual efforts made in pursuit of such goals is very difficult (Evan, 1992).

Having completed the literature review, we found that there was a significant research and publication gap concerning the issues of quality objectives. Quality objectives have not yet been a separate subject of research.

The conducted literature review shows that the aforementioned attributes of quality objectives should be regarded as declaratory. The frequently appearing attributes such as measurability, ambition, clarity and realism are also relevant for strategic and financial objectives. However, the available publications on the subject do not refer to any empirical studies aimed at determining whether quality objectives are characterized by such attributes. From the point of view of the research objectives, we will be interested in whether quality goals are objective and measurable. If they are to fulfil a motivational function, it is their objectivization and subsequently their connections with strategic objectives (as indicated in the requirements of ISO 9001) that will play an important role. As far as the motivational function of quality objectives is concerned, it is worth noting that so far various research and theories have often focused on not so much quality objectives but rather general organizational goals and, in the case of psychological literature, other goals such as personal and life goals. We are interested in who sets quality objectives (to what extent they are established in cooperation with employees), how objective and measurable they are and what conditions have to be met for quality objectives to acquire a motivational function.

\section{Methodology}

We started our research with a literature review. The literature on the subject was reviewed in the course of the following stages: (1) selecting key words (quality objectives, theories of objectives, bonus, remuneration and quality management systems), (2) searching for works containing the selected key words in the following databases: Academic Search Ultimate, including Business Source Ultimate, Education Resources Information Center, AGRICOLA,

\section{Quality objectives in management systems}


IJQRM

39,1

120

Green FILE, and Google Scholar, (3) becoming familiar with the returned publications, (4) reviewing the publications, (5) preparing a map of the available literature, (6) summarizing the selected publications and (7) arranging the collected research material. The applied procedure is consistent with the general methodology of research in management sciences (Easterby-Smith et al., 2015).

We formulated the following research questions:

(1) How are quality objectives set in Polish enterprises?

(2) What are the attributes of established quality objectives?

(3) What conditions have to be met for quality objectives to acquire a motivational function?

Based on the conducted literature review, we formulated the following assumptions:

(1) Quality objectives are set by top managers and subsequently communicated to employees (ISO 9001:2015, Quality Management Systems). They are largely defined by customers, system users and other stakeholders (Djouab et al., 2016).

(2) Quality objectives are measurable and objective mainly in industrial enterprises where it is possible to use hard process measurement data (Tadic et al., 2013; Deming, 2012; Carson and Carson, 1993).

(3) Quality objectives can perform a motivational function (Bugdol, 2014; Varela and Pacheco, 2018; Whitaker and Levy, 2012) provided that a remuneration system is regarded as just and quality objectives are both objective and measurable.

We used a triangulation approach in our research, which is a frequent methodological approach geared to objectivity and enrichment of the research process (Mertens and HesseBiber, 2012). The scope of triangulation included the research methods and obtained data.

After identifying the research gap and formulating the assumptions and research questions, we decided that the survey method would be the most appropriate for meeting our objectives. The used research procedure is characteristic of social sciences and consistent with the principles described by Babbie (2004). We concluded that it was appropriate for gathering such data that could not be obtained by means of observations. We developed a questionnaire as a basic research tool. To ensure the validity of the research data we paid special attention to the correct structure and validation of the questionnaire. Particularly interesting issues were selected already at the literature review stage. We are both active auditors of quality systems. Our experience gained from interviews, observations and examination of quality system documentation undoubtedly influenced the final shape of the questionnaire. Developing its content, we took into account the recommendations included in "The Practice of Social Research" by Babbie (2004). We aimed to ensure that the questions were relevant and avoided negative forms, ambiguous questions and concepts in order to obtain the optimum format of the questionnaire. After the initial version of the questionnaire was prepared, it was tested in a pilot survey. The closed, semi-open and open questions were formulated on the basis of the literature review and our notes on conducted quality system audits. The questionnaire items were prepared on the basis of the current theoretical knowledge of the subject under investigation and in accordance with the rules described in the literature, allowing the minimization of errors related to their interpretation by the respondents (Osterlind, 2002). The whole prepared questionnaire was divided thematically in accordance with the proposed assumptions. In the questionnaire validation procedure, we used the reliability test formula (where the survey was conducted once) based on the split-half method (Steyerberg et al., 2001). Estimating reliability consisted in dividing the questionnaire 
into two parts, examining all respondents and then correlating the results obtained in both parts. The result of correlation was $r=0.84$, which indicates a high measurement accuracy of the questionnaire. In the questionnaire validation process, a pilot study was also used in eight of the surveyed enterprises, which was followed by necessary adjustments (Presser et al., 2004). In the analysis of correlations among the selected variables related to the motivational function of quality objectives, we used Spearman's correlation coefficient.

As a complement to the survey method, we used the exemplification method, which aims to additionally illustrate formulated hypotheses or research assumptions and to justify them with certain properly selected examples (Kazmierska, 2018). This method is not a complete case study but rather a deliberately and selectively applied approach serving to enrich the explanation of the studied reality.

The basis for the application of the exemplification method was our personal participation in management system certification audits in some of the surveyed companies during which, in accordance with the requirements of the ISO 9001:2015 standard, the establishment and pursuit of quality objectives is obligatorily analysed (ISO 9000:2015, Quality Management Systems). Thus, the data necessary for the application of exemplification was obtained through such research techniques as participatory observations, reviews of documents, interviews with persons responsible for the maintenance and improvement of quality management systems. These were, therefore, typical qualitative research techniques (Williams, 2011).

We combined the aforementioned research methods at the level of research design, sample selection, data collection techniques and data analysis. This provided us with benefits typical of triangulation, such as data confirmation and a more complete explanation of the problems under investigation based on the results of the data analysis (Abdalla et al., 2018; Jack and Raturi, 2006; Mertens and Hesse-Biber, 2012). By way of exemplification, we illustrated in particular these research strands which, in the light of the results of the survey, seemed unclear, questionable or indicated the existence of organizational paradoxes.

\subsection{A selection of research samples and a description of respondents}

We applied a non-probabilistic sampling scheme, taking into account the availability of the surveyed companies and their propensity to participate in the survey. It was therefore a purposeful, occasional scheme (Babbie, 2004).

It was assumed that the organizations covered by the research had implemented and continued to maintain a quality management system based on the ISO 9001 standard. This was a key assumption as to the selection of the sample because only such companies are obliged to set quality objectives (ISO 9001:2015, Quality Management Systems). From this point of view, it can be said that the companies selected for the research constituted so-called typical entities with respect to the criterion of the existence of quality objectives (Banerjee et al., 2009).

The sampled entities were companies having quality management systems consistent with the ISO 9001 standard, holding certificates issued by organizations accredited by the Polish Centre for Accreditation.

A formal management system certification process carried out by an independent and professional organization authenticates the application of ISO principles in the surveyed enterprises.

Consequently, 92 companies were qualified for the research, including 49 manufacturing and 43 service companies. We also ensured the correct selection of respondents, who were (regardless of their position) persons competent in the issues under examination, who had knowledge of quality objectives and their role in quality management systems. The respondents for each of the surveyed enterprises were selected using the procedure of consultations with the management representatives responsible for quality. These

\section{Quality objectives in management systems}


IJQRM

39,1

122

representatives were deliberately excluded from the group of respondents due to justified fears of subjectivity of their opinions, resulting from their direct responsibility for the state of the implementation and maintenance of quality management systems. The authors received responses from 277 persons asked to fill in the questionnaire. The questionnaires were sent to the participants and returned by them by mail. There was a slight majority of men -142 persons or $50.9 \%$ of the sample. There were 137 women, who constituted $49.1 \%$ of the sample. The work positions held by the respondents are presented in Table 1.

A considerable part of the respondents represented the production sector (88 persons) or fulfilled the role of specialists (82 persons). Fewer respondents worked in administration (45 persons) or held middle-level managerial positions (35 persons). Direct customer service workers and top managers had the smallest groups of representatives (11 persons and 5 persons respectively). Furthermore, the sample included 11 persons that did not hold any of the general positions specified in the table.

The decisive majority (179 persons) had higher education; 67 respondents had secondary education and 31 respondents - vocational or lower-level education.

The in-depth qualitative research with the use of the previously discussed method of exemplification was carried out in 6 out of 92 surveyed companies, including three manufacturing and three service companies, taking advantage of the authors' presence in these companies in connection with the certification audit processes for their compliance with the ISO 9001:2015 standard. The characteristic features of these enterprises are presented in Table 2.

\section{Results}

\subsection{Setting quality objectives in the surveyed enterprises}

The majority of the respondents confirmed that quality objectives were set in their companies (Figure 1).

\begin{tabular}{lcc}
\hline Position & Number $(N)$ & Percentage (\%) \\
\hline Production worker & 88 & 31.8 \\
Customer service worker & 11 & 4.0 \\
Specialist & 82 & 29.6 \\
Administrative worker & 45 & 16.2 \\
Middle-level manager & 35 & 12.6 \\
Top manager & 5 & 1.8 \\
Others & 11 & 4.0 \\
Total & 277 & 100.0 \\
\hline
\end{tabular}

Table 1.

The positions held by the respondents

\begin{tabular}{lllc}
\hline Company & Sector & Object of activity ${ }^{*}$ & $\begin{array}{r}\text { Number of } \\
\text { employees }\end{array}$ \\
\hline P1 & Industry & Manufacture of paper products & 520 \\
P2 & Industry & Manufacture of pressure equipment and railway tankers & 680 \\
P3 & Industry & Manufacture of valves and gates for the energy, chemical, & 96 \\
P4 & Service & Retrochemical and shipbuilding industries & 245 \\
P5 & Service & Provision of rail welding staff. Employment services & 190 \\
P6 & Service & $\begin{array}{l}\text { Provision of road transport services as well as cars, vans and } \\
\text { trucks forwarding services }\end{array}$ & 65
\end{tabular}

Note(s): "The object of activity was identified in accordance with the scopes of approval as stated on certificates of compliance with the ISO 9001:2015 standard 


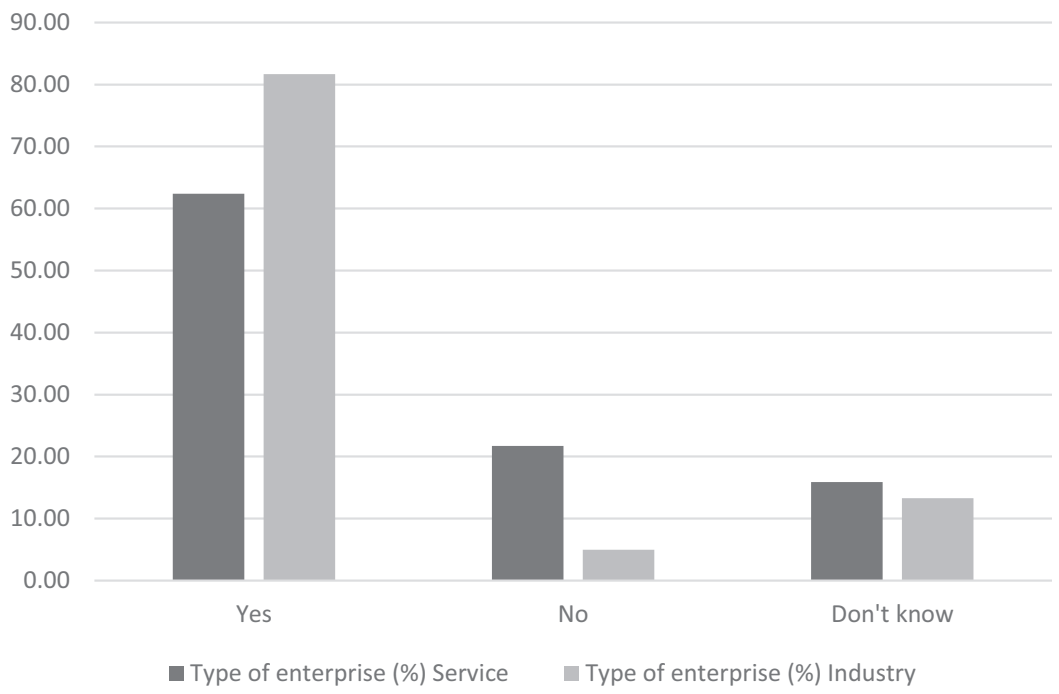

Quality
objectives in
management
systems

123

Figure 1.

The respondents' answers on whether quality objectives are set in the surveyed enterprises - the distribution of the answers by enterprise type

However, it is worth emphasizing that since only companies having a quality management system consistent with the ISO 9001:2015 standard were surveyed, what is puzzling is the answers indicating that in some of these companies quality objectives had not been set or that the respondents were not aware of the fact that they had been set. If this is true that some companies do not establish quality objectives, it would indicate that $21.7 \%$ of the surveyed service companies and $5 \%$ of the production companies do not meet the mandatory requirements of the ISO 9001:2015 standards. On the other hand, the respondents' answers indicating a lack of knowledge of the setting of quality objectives may signal the existence of problems with communicating such objectives to employees.

A partial explanation of the above problems was possible thanks to our in-depth qualitative research.

In the company P1, quality objectives had been established. However, during the course of the survey we became aware of very different levels of employees' awareness of such objectives depending on the location of their workplaces. In the company headquarters, the awareness of quality objectives was complete. On the other hand, the production plant located in another town was oriented towards pursuing objectives related to productivity rather than quality. Asked about quality objectives, a manager in the production plant answered, Yes, maybe they've been set. Id probably know if we failed to meet them.

The company P2 is a completely different case. The survey conducted there showed a perfect knowledge of quality objectives among all respondents. They stressed that due to their company's production profile and resultant audits or inspections, they were frequently "examined" in quality objectives by numerous inspectors, auditors as well as customers and suppliers. A management representative said, Everyone in this company will recite all its quality objectives at any time of day or night, without an error. Not being aware of such objective could cost us a lot, including the loss of strategic customers.

When we were conducting the research the company P3 was struggling with significant financial problems resulting from a restructuring programme. During a review of the corporate documentation and interviews with managers and employees we noticed a very low degree of process digitization and the use of traditional forms of communication based on 
IJQRM

39,1

124

words written on paper. The only place where quality objectives were clearly visible was the trade union announcement board.

The company $\mathrm{P} 4$ was a model example of how to communicate quality objectives effectively and ensure that they are known throughout the organization. In that company, once a month, employees underwent a mandatory online training course that ended with a test. Among the issues covered by the training were quality management issues, including quality objectives. All newly hired employees were also introduced to quality objectives.

The company P5 is a leader in its sector. Its employee bonus system is based on management by objectives. Due to the high level of liability for the quality of provided services (rail welding), the fulfilment of quality objectives is among the company's top priorities. The share of these objectives in the structure of bonus objectives was included in individual contracts with employees.

In the company P6, the main objective was to minimize transport damage. The awareness of this objective was confirmed in interviews by the drivers employed in this company and administration employees responsible for contracts with customers. Other employees and even some management representatives were not aware of it. The problem is best illustrated by the following statement made by a purchase specialist: I $m$ not interested in any quality objectives, if they exist at all. My job is to buy well and cheaply. This utterance highlights the isolation of individual employees and the lack of management integration in the company.

The respondents claimed that targets were established mainly by top management and/or owners (Table 3 ).

In a decidedly small number of enterprises, quality objectives are set by management together with employees $(11.9 \%$ ) or quality objectives result from proposals submitted by the executive personnel $(2.2 \%)$. This means that quality objectives are usually not set in cooperation with employees and the level of employee participation in this area is low. Nor does the conducted survey indicate that external stakeholders are involved in setting quality objectives.

A slightly different picture of the issues under investigation was revealed in the course of the in-depth qualitative research. It confirmed in each of the six surveyed companies that quality objectives were formally formulated by management or owners. However, interviews with managers and specialists of these companies indicated that external stakeholders had an indirect but significant influence on the definition of quality objectives. In the company P1, production quality objectives depended on the changing parameters of raw materials purchased from cellulose suppliers; in the company P2, the technical requirements formulated by strategic customers (mainly global fuel companies) were important in establishing quality objectives and in the company P3, it was inspection units performing qualitative product acceptance procedures that influenced the identification of quality objectives. In the service companies, quality requirements affecting the determination of quality objectives were included in contracts with customers. In the company P4, such requirements were dependent on the current situation on the labour market and concerned changing expectations regarding the supply of temporary workers. The company P5 offered its services mainly by winning large tenders for the award of contracts. The company's

Table 3.

The respondents' about the persons responsible for setting quality objectives

\begin{tabular}{lcc}
\hline Answer & Number $(N)$ & Percentage (\%) \\
\hline Management & 147 & 53 \\
Owner & 91 & 32.9 \\
Management together with employees & 33 & 11.9 \\
Quality objectives result from proposals made by the executive staff & 6 & 2.2 \\
Total & 277 & 100.0
\end{tabular}


customers were often advised by consultants in defining quality requirements. Finally, in the company P6, the requirements applicable to transport damage limits were defined by its strategic customers, especially automotive companies.

\subsection{Attributes of quality objectives in the surveyed enterprises}

The majority of the respondents claim that quality objectives are measurable and objective (63.3\% for service and $81.4 \%$ for manufacturing companies (Figure 2).

The higher percentage of positive opinions in the case of industrial companies is not surprising. This is largely due to the fact that they produce tangible products.

Evidence of the measurability of quality objectives in manufacturing companies was also provided by the in-depth research conducted by the authors. The key quality objectives in the surveyed enterprises included the following: in the company P1 - achieving a certain level of manufacturing products in the best grade, lowering the ratio of customer complaints to the total sales volume, achieving an appropriate level of customer satisfaction and lowering the consumption of energy in production processes; in the company P2 - eliminating customer complaints during the warranty period, extending the warranty period in consequence of improvements in production processes, eliminating errors in ongoing and final quality control inspections, ensuring a certain level of customer loyalty, reducing the number of noncompliant deliveries, diversifying material supply sources, internalizing all manufacturing processes in the company and automating quality control and welding processes and in the company P3 - reducing the number of customer complaints, limiting the range of assortment, maintaining customer satisfaction at a certain level and increasing flexibility of material supplies.

Measurable quality objectives were also present in the service companies participating in the survey, although they were less numerous. In the company P4, the main quality objective was providing temporary workers demanded by customers at a certain percentage and building a digital platform for handling transactions with customers and employees. The company P5 represented a very strong orientation towards financial results. Its quality objectives were strictly financially driven and concerned the following: reducing the costs of customer complaints and increasing the efficiency of the basic process, i.e. the welding of rails in a unit of time. The company P6 pursued the objectives of preventing damage occurring in transport and ensuring the timeliness of provided services.

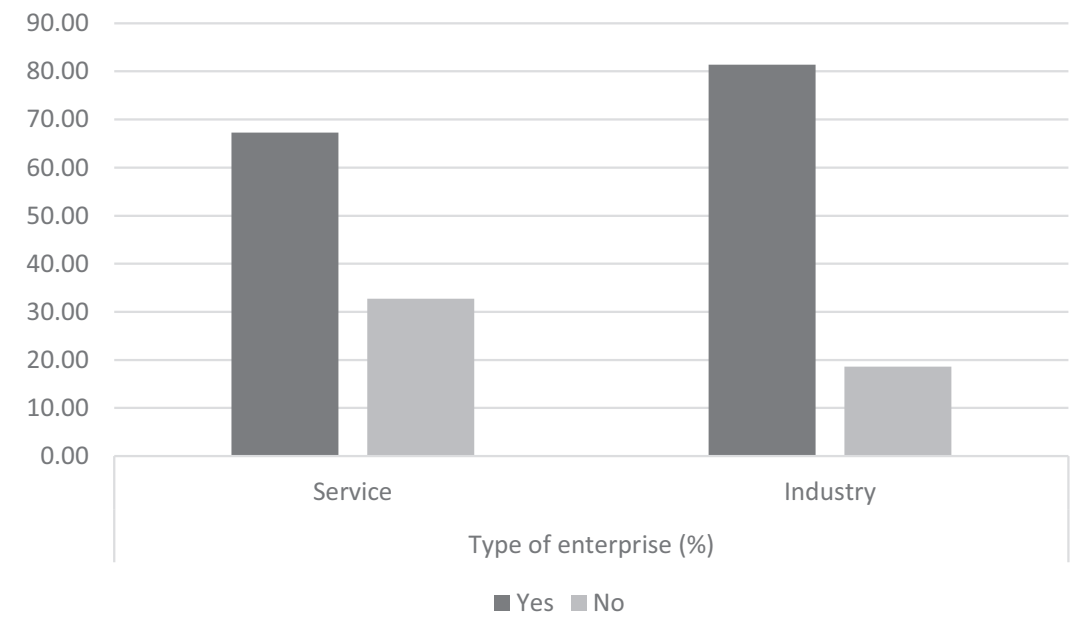

Quality objectives in management systems

t 
IJQRM

39,1

126

Table 4 presents the respondents' answers to the question about connections between quality objectives and strategic objectives in the surveyed enterprises.

The majority of the respondents confirmed that quality objectives in force in their companies were linked to strategic objectives, which would confirm such companies' compliance with the requirements specified in the ISO 9001:2015 standard.

In the six companies covered by the in-depth research, we also confirmed the existence of such relationships. We were interested primarily in how the link between these two groups of targets was ensured. The research showed that a different solution was applied in each of the companies. The enterprise P1 followed a rather conventional approach. Quality objectives were defined during a meeting having the status of a management review, in accordance with the ISO 9001:2015 requirements. The presence of all top managers at the review and their participation in defining quality objectives resulted in some of them being related to strategic objectives. In the company P2, for several years the management had been using Balanced Scorecards in planning and monitoring its activities. Quality objectives were included in the overall set of its corporate objectives. The model of the used tool caused the integration of the quality objectives with the strategic objectives. Moreover, some of the quality objectives, such as the internalization of manufacturing processes, were simultaneously strategic objectives. In the company P3, we did not identify any conscious attempts to integrate quality objectives with strategic ones. Nevertheless, an interview with the company's technical director about the current priorities confirmed that one of the quality objectives consisting in increasing the flexibility of deliveries was regarded as strategically important, as its accomplishment would be one of the ways to improve liquidity and address the financial problems of the company.

Our researched showed that the company P4, an employment agency, had two quality objectives that were at the same time strategic objectives. This was so because the company operated in a sector characterized, in accordance with Porter's concept (1985), by low entry barriers, where competition was strong. The President of the Management Board illustrated the situation with the following statement: If there are several thousand employment agencies in Poland, there are basically two directions of competition. One direction is to pursue economies of scale. Unfortunately, this strategy leads to very low margins. We prefer to focus on quality and convince customers that it is worth paying more for our professionalism, efficiency, and compliance with the law. It can therefore be concluded that the enterprise P4 adopted a qualitative leadership strategy based on the Ansoff's concept (1980), which resulted in the identity of its quality objectives and strategic objectives. Quality objectives were not directly correlated with strategic objectives in the company P5. The company's previously indicated strong orientation towards increasing its revenues and value resulted in the dominant position of its financial objectives. The fact that the quality objectives had been given a partially financial dimension caused these objectives to become subordinated to the overall financial objectives. The quality objectives of the company P6 were also included in its contracts with key customers and failure to meet them would allow the termination of such contracts. Thus, ensuring the achievement of quality objectives was an important factor contributing to the continuity of the company's activities and even its existence. This is also due to the fact that the company provided its services to only a few "big" customers, so the loss of even one of them could cause serious problems.

Table 4.

The respondents' opinions on connections between quality objectives and strategic business objectives

\begin{tabular}{lcc}
\hline Answer & Number $(N)$ & Percentage (\%) \\
\hline Yes & 185 & 66.8 \\
No & 26 & 9.4 \\
Don't know & 66 & 23.8 \\
Total & 277 & 100.0
\end{tabular}


4.3 Motivational function of quality objectives in the surveyed enterprises

A difficult research task was to assess the motivational function of quality objectives. The conducted research shows first of all that in most cases quality objectives are taken into consideration in determining managers' remuneration (Figure 3).

Thus, it can be assumed that top managers should care about achieving quality objectives. A slightly higher percentage of positive responses in the case of the service companies may indicate a more flexible design of remuneration mechanisms in these companies. In the six additionally surveyed companies, we found a different situation in terms of the way quality objectives were taken into account in the remuneration of top management. In the companies $\mathrm{P} 1$ and $\mathrm{P} 2$, this was reflected in the annual bonus. Because of the difficult financial situation of the company P3 at the time when the research was being carried out, its managers' salaries consisted of a fixed part only. On the other hand, in the service companies P4, P5 and P6, the degree of achieving quality objectives influenced the amount of a quarterly bonus for the top management.

The respondents were also asked about the impact of the achievement of quality objectives on the amount of bonuses granted to employees. It turned out that in the set of criteria determining the award of bonuses, the achievement of quality objectives was not assigned the greatest importance (the result of $27.7 \%$ taking into account all elements on the basis of which these objectives are established, e.g. the number of failures). At the same time, an assessment of the immediate superior was indicated as the main factor in awarding bonuses to employees (significance $-55.7 \%$ in the service companies and $64.2 \%$ in the industrial firms). The relatively important factors include also the performance of additional tasks (39.8\% in total) and the lack of sickness-related absence (36.3\% in total).

It can be assumed that if something is to motivate employees to work, it should be fair. Procedural justice related to the award of bonuses will appear if award rules are specified in a formal document.

Table 5 presents the respondents answers to the query about a formalized bonus award procedure.

In the majority of the enterprises participating in the survey $(68.6 \%)$, the rules for awarding bonuses were formally established.

In the six companies that were subject to the qualitative research, we checked how the rules for awarding bonuses had been formalized (we omitted the company P3, where bonuses

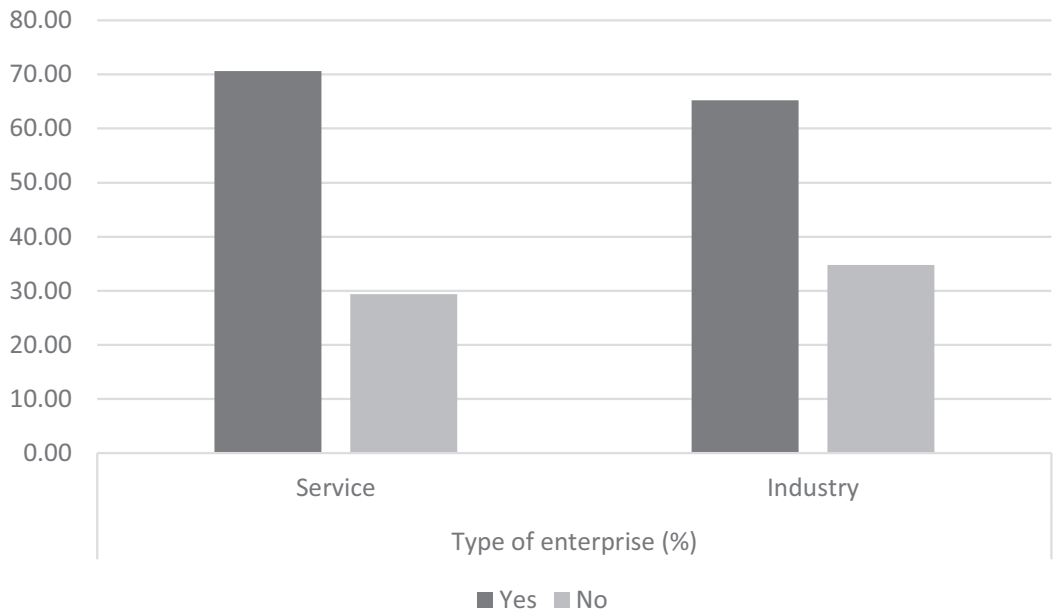

Quality objectives in management systems

127
Figure 3.

The respondents' opinions on using quality objectives as a criterion in

determining the remuneration of top management - the distribution of the answers by enterprise type 
IJQRM

39,1

128

were not paid). It turned out that the companies $\mathrm{P} 1$ and $\mathrm{P} 2$, characterized by long-established traditions, had included bonus award rules in their remuneration regulations, which had had to be agreed with the trade unions. In his interview, the President of the Management Board in the company P2 said: In our company, the bonus award rules are transparent. The problem is sometimes negotiation with the trade unions, which are used to fixed bonus amounts and find it difficult to accept the variable component. The service companies $\mathrm{P} 4, \mathrm{P} 5$ and $\mathrm{P} 6$ represented a different approach to formalizing bonus award rules. The enterprise P4 had work performance standards applicable to its particular departments and bonus award rules were included in such standards. The company P5 specified its bonus award rules in individual contracts with employees. Consequently, our research showed considerable discrepancies among the bonus award thresholds in the particular departments. In the company P6, there were separate bonus award rules for administrative employees and for drivers. They were established by the owner in the annual remuneration policy.

We also checked the respondents' opinions on the allocation of tasks aimed at achieving the formulated objectives, i.e. whether they perceived task allocation as fair (Figure 4).

It turned out that the opinions of employees of both types of companies are strongly divided. For both groups of companies, a significant proportion of the respondents, i.e. about a half of them, felt that the allocation of tasks was unfair.

Knowing the presented research results, we interviewed the HR managers of the six companies and asked them about the key reasons for the unfair allocation of tasks. In the company $\mathrm{P} 1$, frequent production downtime situations caused by machine failures were indicated. In such cases, particularly experienced employees are used to repair failures. In the company P2, quite frequent cases of uneven task allocation were confirmed, which was related to the introduction of numerous product innovations. And similarly to the company

Table 5.

The respondents' answers to the question about formal bonus award rules specified in organizational documentation

\begin{tabular}{lcc}
\hline Answer & Number $(N)$ & Percentage $(\%)$ \\
\hline Yes & 190 & 68.6 \\
No & 87 & 31.4 \\
Total & 277 & 100.0 \\
\hline
\end{tabular}

Figure 4.

The respondents' opinions on the fairness of the allocation of tasks among employees - the distribution of the answers by enterprise type

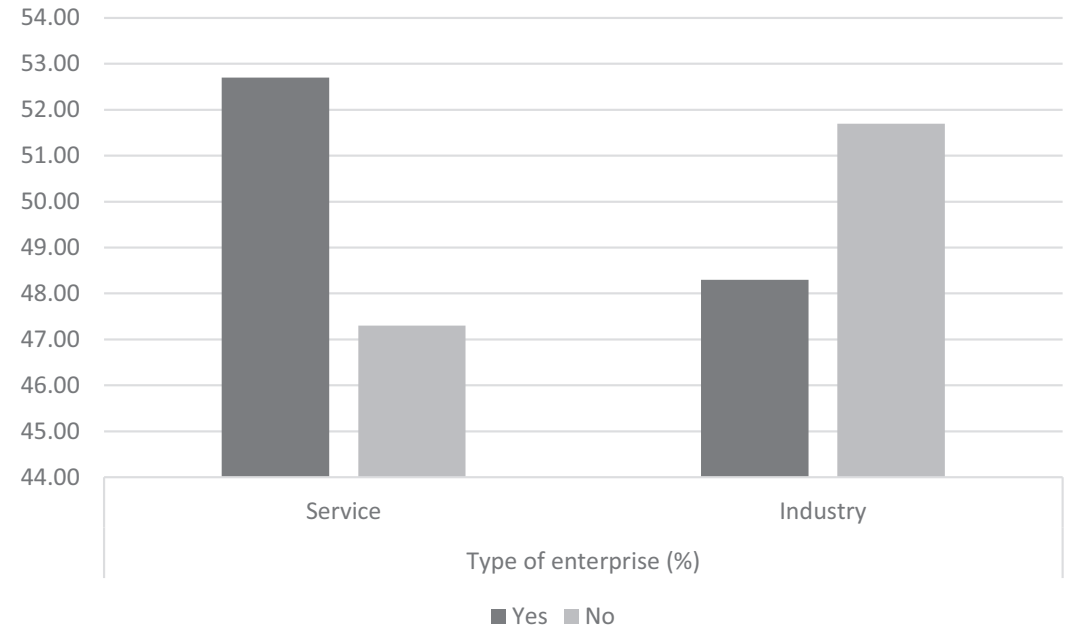


$\mathrm{P} 1$, such problems become the responsibility of employees with the greatest experience. In the company P3, the unfair allocation of tasks resulted from the fact that, in consequence of the implemented savings programme, employees with broad competences (mainly in the areas of administration and management) were assigned additional tasks. In the company P4, we confirmed a temporary differentiation in the level of tasks allocated to regional managers resulting from differences in the sizes of the geographical regions served by them. In the company P5, we indicated a differentiation resulting from some employees' more frequent absences from work. Meanwhile, a differentiation in the allocation of tasks in the company P6 resulted from qualifications held by drivers.

The last element of our research was to find out what motivated the respondents to improve quality in order to establish a catalogue of such factors (Figure 5).

Bonus award systems discussed earlier were one of the most frequently mentioned factors. Interestingly, intangible factors such as praise of superiors or autonomy in the form of self-control were also mentioned frequently.

In the production companies P1, P2 and P3, we confirmed the importance of self-control. It turned out that in each of these enterprises the right to self-control was granted to production employees with a very high level of competence. The company P2 had introduced some elements of lean manufacturing, so employee competence matrices were formalized. Therefore, it can be assumed that self-control was an expression of appreciation for the competence of employees in the companies participating in the research and was a distinguishing feature in relation to other employees. The motivational effect of self-control was associated in the surveyed companies with the sense of responsibility for quality and prevention of errors.

The service companies P4, P5 and P6 used various means of distinguishing employees, with the factor of praise by superiors acquiring a visible and formalized form. The company $\mathrm{P} 4 \mathrm{had}$ introduced a motivational programme called "The Employee of the Month". Candidates for the

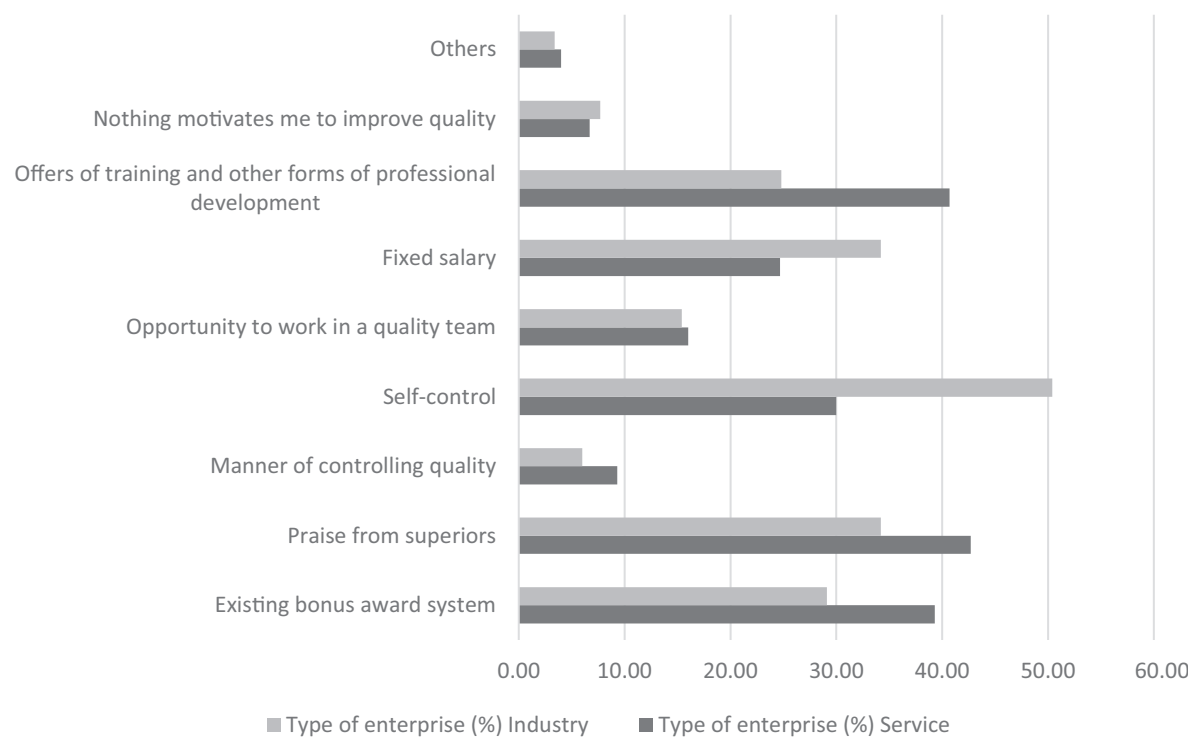

Note(s): *The percentage points do not add up to give 100 because the respondents were able to choose up to three answers
Quality
objectives in
management
systems

129
Figure 5.

The respondents' answers to the question about factors motivating them to improve quality - the distribution of the answers by enterprise type 
IJQRM

39,1 distinction were nominated by unit managers. The company P5 was running a programme called "The Creative Sales Representative". Similarly to the programme mentioned above, candidates for the award were nominated by the management. Finally, "The Least Damage" was the name of the motivational programme launched in the company P6 and aimed at its drivers only. Every quarter, on the basis of data concerning transport damage, the company announced the winner, i.e. the driver who had generated the least transport damage.

An analysis of correlations among the selected variables related to the motivational function of quality objectives

In order to objectivize the third assumption, we examined statistical relationships between the following:

(1) The objectivity and measurability of quality objectives and:

- The perceived fairness of the remuneration system,

- The motivational significance of the remuneration system,

(2) The inclusion of quality objectives in the granting of bonuses and:

- The perceived fairness of the remuneration system,

- The motivational significance of the remuneration system.

After a preliminary check of the distributions of the examined variables, it was found that these distributions differed significantly from a normal distribution. For this reason, we considered Spearman's correlation coefficient as an adequate measure of the level of correlation. It can be applied when there is a significant proportion of outliers. Spearman's correlation coefficient $r_{s}$ is calculated from the following formula:

$$
r_{s}=1-\frac{6 \sum_{i=1}^{n} d_{i}^{2}}{n\left(n^{2}-1\right)}
$$

where:

$d_{i}^{2}$ - square difference between the two ranks of each observation

$n$ - number of observations.

Spearman's correlation coefficient $r_{\mathrm{s}}$ takes values from the range $<-1,1>$. The closer it is to 1 or -1 , the stronger the relation under analysis. More specifically, obtained values of $r_{s}$ are interpreter as follows:

(1) $<0.2$ - weak correlation (practically no relationship),

(2) $0.2-0.4-$ low correlation (clear relationship),

(3) $0.4-0.6$ - moderate correlation (significant relationship),

(4) $0.6-0.8$ - high correlation (considerable relationship),

(5) $0.8-0.9$ - very high correlation (very strong relationship),

(6) 0.9-1.0 - practically complete correlation. 
Below we present the obtained results of the correlation analysis calculated by means of the Statistica software (Table 6).

The performed correlation analysis showed a strong, statistically significant correlation, in particular between the objectivity and measurability of quality objectives and the justice of the remuneration system as perceived by the respondents $\left(r_{s}=0.892 ; p=0.000067\right)$, as well as between the objectivity and measurability of quality objectives and the motivational significance of the remuneration system $\left(r_{s}=0.819 ; p=0.000092\right)$. It turned out that the objectivity and measurability of quality objectives were independent variables that could strongly influence employees' perception of remuneration systems. This confirms that what is important from the perspective of the respondents is the formulation of objectives and, therefore, activities taking place during the planning phase. Weaker correlations occurred between the inclusion of quality objectives in bonus allocation and the perceived fairness of the remuneration system $\left(r_{s}=0.532 ; p=0.000198\right)$, as well as the inclusion of quality objectives in bonus allocation and the motivational significance of the remuneration system $\left(r_{s}=0.475 ; p=0.000212\right)$.

\section{Conclusions}

Our first research assumption was only partially confirmed. Objectives are established mainly by top management, but the very process of communicating them is insufficient. Also, the needs of system users are not taken into account. The process of setting quality objectives is relatively correct, but only from a procedural point of view. Despite the fact that a considerable part of employees are familiar with quality objectives, the process of setting them leaves much to be desired. The rate of employee participation in setting quality objectives is rather low. Not all superiors set quality objectives in cooperation with employees. Things important for managers include employees' good attendance record, avoidance of accidents and willingness to take up additional tasks. Thus, maybe the real problem is work discipline. Even if this is the case, the problem is not formal discipline (none of the respondents received a penalty under the Labour Code).

It was surprising that employees in organizations with implemented quality management systems were not familiar with quality objectives. The identified communication problems may, in fact, indicate a low (perhaps only documentary) level of system implementation, but they may also show disregard for systems or a low quality of audit services (after all, quality awareness verification consists, among other things, in checking whether everybody is familiar with quality objectives).

The results indicating the dominant role of managers in setting quality objectives confirmed the results of previous research.

Our second research assumption was also confirmed in part.

\begin{tabular}{|c|c|c|c|c|c|}
\hline Pair of variables & & $\begin{array}{c}N \\
\text { important }\end{array}$ & $\begin{array}{c}R \\
\text { Spearman }\end{array}$ & Level $p$ & \\
\hline $\begin{array}{l}\text { Objectivity and measurability of } \\
\text { quality objectives }\end{array}$ & $\begin{array}{l}\text { Perceived fairness of the } \\
\text { remuneration system }\end{array}$ & 277 & 0.892137 & 0.000067 & \\
\hline $\begin{array}{l}\text { Inclusion of quality objectives in } \\
\text { bonus allocation }\end{array}$ & $\begin{array}{l}\text { Perceived fairness of the } \\
\text { remuneration system }\end{array}$ & 277 & 0.532344 & 0.000198 & \\
\hline $\begin{array}{l}\text { Objectivity and measurability of } \\
\text { quality objectives }\end{array}$ & $\begin{array}{l}\text { Motivational significance of the } \\
\text { remuneration system }\end{array}$ & 277 & 0.818892 & 0.000092 & $\begin{array}{r}\text { Table } 6 . \\
\text { The results of the }\end{array}$ \\
\hline $\begin{array}{l}\text { Inclusion of quality objectives in } \\
\text { bonus allocation }\end{array}$ & $\begin{array}{l}\text { Motivational significance of the } \\
\text { remuneration system }\end{array}$ & 277 & 0.475321 & 0.000212 & $\begin{array}{l}\text { correlation analysis for } \\
\text { the selected variables }\end{array}$ \\
\hline
\end{tabular}

\section{Quality objectives in management systems}


IJQRM

39,1

132

Quality objectives are measurable and, in the opinion of employees, objective, although not very ambitious as they are not based on benchmarking analyses. The majority of the respondents were convinced that measuring customer satisfaction could provide objective results. They were of the opinion that quality objectives were linked to strategic objectives $(66.3 \%)$. This means that there are hypothetically three possibilities: the organization does not meet the criteria of the standard (quality objectives have to be linked to strategic goals), or the respondents and perhaps quality managers do not have sufficient knowledge of the matter, or - if the survey results are to be accepted - employees do not perceive strategy as something very important. It is worth noting that despite the fact that quality objectives are mostly established by the management, they are largely assessed as objective. What is more, their objectivization and recognition are due, among other things, to the fact that the rules for awarding bonuses are defined in the organizational documentation.

The third research assumption revealed only the conditions that have to be met if quality objectives are to fulfil a motivational function (cf. the practical recommendations below).

If quality objectives are to fulfil a motivational function, they need to be regarded generally as objective and bonuses, which depend, among other things, on the achievement of quality objectives, should be rewarded on the basis of work regulations, which is important for maintaining the principles of procedural justice. There is a statistical relationship between the objectivity and measurability of quality objectives and the fairness of the remuneration system as perceived by the respondents, as well as between the objectivity and measurability of quality objectives and the motivational significance of the remuneration system.

For quality objectives to fulfil a motivational function, they should be objective and measurable. Also, the allocation of tasks among employees needs to be fair. Unfortunately, at present, in just a half of organizations, the allocation of tasks is perceived as fair ( $52.7 \%$ in the service sector, $48.3 \%$ in the manufacturing sector). Furthermore, quality objectives have to play a greater role in remuneration systems. They are included in remuneration systems for managers and in bonus award systems for all other employees. However, their assessment takes place once a year during management reviews and the amount of a bonus itself does not depend to a significant extent on the accomplishment of quality objectives. It turned out that in the set of criteria determining the award of bonuses, the achievement of quality objectives was not assigned the greatest importance (the result of $27.7 \%$, taking into account all elements on the basis of which these objectives are established, e.g. a number of failures).

Previous studies have shown that one of the main problems that hinders the inclusion of quality objectives in remuneration systems is the lack of objective quality measurement instruments (Evan, 1992). However, it is difficult to conclude that this is the reason why quality objectives do not play the dominant role among bonus award criteria. It turns out that superiors pay greater attention to those elements that are easy to assess and that they probably have to deal with on a daily basis (e.g. employees' presence at work).

It was a big surprise to find that quality objectives were taken into account in top management remuneration systems. We do not know to what degree these objectives fulfil a dominant or equivalent function in the overall set of the factors determining the amount of remuneration. It should be noted that previous studies indicated that the amount of remuneration depended mainly on the achievement of financial objectives such as operating profit, net profit, revenue per employee, ROCE (return on capital employed) or EBITDA (earnings before interest, taxes, depreciation and amortization), performance measures (e.g. earnings per share), performance levels and pay-performance structures (different amounts earned at different performance levels) (Bakó and Kálecz-Simon, 2017; Bugdol, 2018; Kim and $\mathrm{Ng}, 2018)$.

On the basis of the research carried out, the following practical recommendations can be formulated: 
Employees should be guaranteed greater participation in setting quality objectives. Ignoring opinions of front-line employees and linking managers' remuneration to the achievement of quality objectives may cause conflicts and put pressure on pursuing shortterm objectives only. At both the normative level (e.g. ISO 9001) and the conceptual level (TQM), what is important is bottom-up initiatives such as taking corrective and preventive measures. The status of such measures is discussed during management reviews. Therefore, when formulating quality objectives, the management should take into account the ideas, opinions and suggestions of those employees who are the closest to the customer and are involved in the performance of daily tasks and operations.

Objective data illustrating the course of processes have to be given more importance in setting quality objectives. Obviously, data of this type are not always easy to obtain in every sector of the economy (monitoring can be a serious problem in service businesses). The use of objective data may to some extent reduce the feeling of injustice and thus prevent a demotivating effect). In both quality management systems and the TQM concept, there is an obvious necessity to monitor processes.

The linking of quality objectives to motivational systems makes sense only if it is possible to estimate the individual contribution of each employee to the execution of tasks and achievement of objectives (self-managing teams can be an exception). Rewarding employees for the achievement of quality objectives is a difficult task. That is why the precursors of TQM advocated fixed remuneration. When employees make an extra effort to achieve quality objectives and someone else in the quality chain makes a mistake or intentionally omits something, there is no extra remuneration despite employees' commitment and dedication.

As the achievement of quality objectives is assessed on an annual basis, its inclusion in the calculation of monthly bonuses leaves much to be desired. Quality objectives can be included in annual or biannual bonus award schemes.

For quality objectives to be motivating, they have to be set a little above the current levels (they have to be slightly excessive). This recommendation is in line with Locke's motivational theory. In the practice of quality management, however, it is important to introduce a progressive remuneration system (otherwise, employees will not be interested in pursuing more difficult objectives). The other important aspects include the allocation and review of objectives, as well as the participation of employees in establishing quality objectives. The application of the QFD (Quality Function Deployment) method is also recommended.

\section{Limitations and further research}

Obviously, the main limitations are caused by the adopted research method. Surveys provide only opinions, often subjective ones. Secondly, the limitations lie in the cultural sphere - only companies operating in Poland participated in the survey. In research on the motivational function of quality objectives, it should be remembered that employees have different objectives and different motives for acting. Some people value their status in an organization or friendships; others are motivated by money or power. That is why it is so difficult to pursue the integration of various objectives - not only formal ones such as quality, environmental or OHS objectives but also hidden ones.

Analysing the collected data, we indicate possible directions of further research in this area:

(1) Linking quality objectives with strategic objectives (such a need is stated in the ISO 9001 standard, but quality audits show that, in practice, employees are rarely familiar with their companies' strategies, while in some cases, e.g. state-owned companies, strategies may be strictly confidential).

(2) The coherence of different objectives in integrated management systems (there is a risk that particular objectives can be mutually exclusive).
Quality objectives in management systems

133 
IJQRM

39,1

(3) The process of setting individual objectives for managers (it follows from the performed observations that such objectives are established for lower-level managers and in such a way that their achievement is relatively easy).

The fact that in most cases objectives are set by the management may result from management styles, lack of trust, divergent interests, but also from habits, necessity, supervisory regulations (e.g. a requirement for board members to set personal objectives). Continued research is therefore needed on both the causes and consequences of establishing objectives by the management. Such research can be conducted based on various theories, particularly the theory proposed by Locke (1978). Another potentially useful theory is the theory of expectations, as it focuses on the anticipations of managers, owners and employees influencing their subsequent behaviours. The theory of counterproductive behaviours can also provide inspiration for research on the complexity of the process of achieving objectives. In quantitative research focusing on factors influencing the whole process of managing objectives (from their establishment to the assessment of their achievement), the systems theory can be extremely useful. The objectives management process is influenced by the elements of both the social subsystem (e.g. trust, a sense of justice, hence values, group standards and interactions) and the organizational and legal subsystem (organizational governance, complexity of processes and structures). This problem can be investigated using a number of approaches (e.g. the functionalist approach, the theory of conflict).

\section{ORCID iDs}

Marek Bugdol Dhttp://orcid.org/0000-0001-9993-7765

\section{References}

Abdalla, M.M., Oliveira, L.G.L., Azevedo, C.E.F. and Gonzalez, R.K. (2018), "Quality in qualitative organizational research: types of triangulation as a methodological alternative", Administração: Ensino e Pesquisa, Vol. 19 No. 1, pp. 66-98, doi: 10.13058/raep.2018.v19n1.578.

Allison, J.H. and Byron, M.A. (1996), "Aligning quality improvement with strategic goals at ANA", National Productivity Review, Vol. 15 No. 2, pp. 89-99.

Ansoff, H.I. (1980), "Strategic issue management", Strategic Management Journal, Vol. 1 No. 2, pp. 131-148, doi: 10.1002/smj.4250010204.

Babbie, E. (2004), Metody Badań Społecznych, PWN, Warszawa.

Bakó, B. and Kálecz-Simon, A. (2017), "Quota bonuses as localized sales bonuses”, Managerial and Decision Economics, Vol. 38, No.7, pp. 964-970.

Banerjee, A., Chitnis, U., Jadhav, S., Bhawalkar, J. and Chaudhury, S. (2009), "Hypothesis testing, type I and type II errors", Industrial Psychiatry Journal, Vol. 18 No. 2, p. 127, doi: 10.4103/09726748.62274 .

Bexelius, A., Carlberg, E.B. and Löwing, K. (2018), "Quality of goal setting in pediatric rehabilitation a SMART approach", Child: Care, Health and Development, Vol. 44 No. 6, pp. 850-856.

Blikle, A.J. (2009), Doktryna Jakości, PWN, Warszawa.

Bugdol, M. (2014), “Cele jakości w systemach zarzạdzania jakością w administracji samorządowej”, Samorzad Terytorialny, No. 3, pp. 57-66.

Bugdol, M. (2018), System zarzadzania Jakościa Według ISO 9001:2015, Onepress, Gliwice.

Carson, P.P. and Carson, K.D. (1993), "Deming versus traditional management theorists on goal setting: can both be right?", Business Horizons, Vol. 36 No. 5, p. 79.

Ceniceros, R. (2001), "Providers' bonus tied to quality, satisfaction”, Business Insurance, Vol. 35 No. 29, pp. 1-2. 
Crosby, P. (1979), Quality Is Free, McGraw-Hill, New York, NY.

Dale, B.G. (1999), Managing Quality, Blackwell Business, London.

Dale, B.G. (2001), Managing Quality, Blackwell Business, London.

Daniel, S., Lee, D. and Reitsperger, W. (2014), "Raising quality consciousness among Chinese manufacturing personnel: testing the effectiveness of performance management tools", Asia Pacific Journal of Management, Vol. 31 No. 2, pp. 549-573.

Deming, E. (2012), Nowa Ekonomia Dla Przemysłu, Rzadu, Edukacji, Opexbooks, Wrocław.

Djouab, R., Abran, A. and Seffah, A. (2016), "Quality objectives are defined by customers, system users, other stakeholders (An ASPIRE-based method for quality requirements identification from business goals)", Requirements Engineering, Vol. 21 No. 1, pp. 87-106.

Easterby-Smith, M., Thorne, R. and Jackson, P.R. (2015), Management and Business Research, Sage, Los Angeles.

Evan, I. (1992), "Paying for quality”, The TQM Magazine, Vol. 4 No. 5, pp. 22-34.

Fishbach, A. (2018), "How to keep working when you're just not feeling it", Harvard Business Review, Vol. 96 No. 6, pp. 138-141.

Foster, J.J. (2003), "Motywacja w miejscu pracy", in Chmiel, N. (Ed.), Psychologia Pracy I Organizacji, GWP, Gdańsk.

Gilliland, S.W. and Landis, R.S. (1992), "Quality and quantity goals in a complex decision task: strategies and outcomes", Journal of Applied Psychology, Vol. 77 No. 5, pp. 672-681.

Hirzalla, M., Bahrs, P. and Cleland-Huang, J. (2014), "Beyond anecdotal thinking: deepening our understanding for achieving quality goals", IEEE Software, Vol. 31 No. 3, pp. 26-29.

Huczynski, A. and Buchanan, D.A. (1991), Organizational Behaviour, Prentice Hall, New York, NY.

Invey, E. (1992), "Paying for quality", The TQM Magazine, Vol. 4 No. 5, pp. 22-34.

Ishikawa, K. (1985), What Is Total Quality Control? the Japanese Way, Prentice-Hall, Englewood Cliffs.

ISO 9000:2015 (2015), Quality Management Systems - Fundamentals and Vocabulary.

ISO 9004:2009 (2009), Managing for the Sustained Success of an Organization - A Quality Management Approach.

ISO 9004:2018 (2018), Quality Management - Quality of an Organization — Guidance to Achieve Sustained Success.

Jack, E.P. and Raturi, A.S. (2006), "Lessons learned from methodological triangulation in management research", Management Research News, Vol. 29 No. 6, pp. 345-357, doi: 10.1108/ 01409170610683833.

Jedynak, P. (2007), Ocena Znormalizowanych Systemów Zarzadzania Jakościa: Instrumenty I Uwarunkowania Wartości, Wydawnictwo Uniwersytetu Jagiellońskiego, Kraków.

Kazmierska, K. (2018), "Doing biographical research-ethical concerns in changing social contexts", Polish Sociological Review, Vol. 3 No. 203, pp. 393-411, doi: 10.26412/psr203.06.

Kim, S. and Ng, J. (2018), "Executive bonus contract characteristics and share repurchases", The Accounting Review, Vol. 93 No. 1, pp. 289-316.

Locke, E.A. (1978), "The ubiquity of the technique of goal setting in theories of and approaches to employee motivation", Academy of Management Review, Vol. 3 No. 3, pp. 594-601.

Madhusree, S. and David, B. (2006), "Pay for performance-a bonus for quality", Journal of Financial Service Professionals, Vol. 60 No. 2, pp. 10-12.

Martínez-Moreno, A. and Díaz, S.A. (2016), "Level of quality management in the municipal sports services, contrast through EFQM excellence model", SpringerPlus, Vol. 5 No. 1, pp. 1-8.

Mendes, E. (2010), "U.S. parents want teachers paid on quality, student outcomes", Gallup Poll Briefing, Vol. 8 No. 25, p. 2.
Quality
objectives in
management
systems

135 
IJQRM

39,1

Mertens, D.M. and Hesse-Biber, S. (2012), "Triangulation and mixed methods research", Journal of Mixed Methods Research, Vol. 6 No. 2, pp. 75-79, doi: 10.1177/1558689812437100.

Oakland, J. (1995), Total Quality Management, Butterworth Heinemann, Oxford.

Osterlind, S.J. (2002), Constructing Test Items, Springer, Dordrecht. doi: 10.1007/0-306-47535-9.

Porter, M.E. (1985), Competitive Advantage: Creating and Sustaining Superior Performance, Free Press, New York, NY, Collier Macmillan, London.

Presser, S., Couper, M.P., Lessler, J.T., Martin, E., Rothgeb, J.M., Bureau, U.S.C. and Singer, E. (2004), "Methods for testing and evaluating survey questions", Public Opinion, Vol. 68 No. 1, pp. 109-130, doi: 10.1093/poq.

Price, F. (2002), "Pojęcie i cele jakości”, in Lock, D. (Ed.), Podręczik Zarzadzania Jakościa, PWN, Warszawa.

Rogala, P. (2019), "There is only one way to excellence”, An Interview with Prof. Jens J. Dahlgaard, Problemy Jakości, No. 2, pp. 17-20.

Shackleton, V. and Wale, P. (2002), "Przywództwo i zarządzanie", in Chmiel, N. (Ed.), Psychologia Pracy I Organizacji, Gdańskie Wydawnictwo Psychologiczne, Gdańsk.

Steyerberg, E.W., Harrell, F.E., Borsboom, G.J.J., Eijkemans, M.J., Vergouwe, Y. and Habbema, J.D.F. (2001), "Internal validation of predictive models", Journal of Clinical Epidemiology, Vol. 54 No. 8, pp. 774-781, doi: 10.1016/S0895-4356(01)00341-9.

Tadic, D., Gumus, A.T., Arsovski, S., Aleksic, A. and Stefanovic, M. (2013), "An evaluation of quality goals by using AHP fusion and TOPSIS methodology", Journal of Intelligent and Fuzzy Systems, Vol. 25 No. 3, pp. 547-556.

Van Meter, K.J., Van Cappellen, P. and Basu, N.B. (2018), "Legacy nitrogen may prevent achievement of water quality goals in the Gulf of Mexico", Science, Vol. 360 No. 6387, pp. 427-448.

Varela, B. and Pacheco, G. (2018), "Comprehensive evaluation of the internal and external quality control to redefine analytical quality goals", Biochemia Medica, Vol. 28 No. 2, pp. 1-11.

Whitaker, B.G. and Levy, P. (2012), "Linking feedback quality and goal orientation to feedback seeking and job performance", Human Performance, Vol. 25 No. 2, pp. 159-178.

Williams, C. (2011), "Research methods", Journal of Business and Economics Research, Vol. 5 No. 3, pp. 65-71, doi: 10.19030/jber.v5i3.2532.

Wruck, K.H. and Jensen, M.C. (1998), "The two key principles behind effective TQM programs", European Financial Management, Vol. 4 No. 3, pp. 401-423.

Wysham, C.H., Pilon, D., Ingham, M., Lafeuille, M.H., Emond, B., Kamstra, R., Pfeifer, M. and Lefebvre, P. (2018), "Quality goal attainment and maintenance in patients with type II diabetes mellitus initiated on canagliflozin or a glucagon-like peptide-1 receptor agonist in an actual practice setting", Current Medical Research and Opinion, Vol. 34 No. 6, pp. 1125-1133.

Zapłata, S. (2018), Projakościowe Zarzadzanie W Organizacji - Czynniki Sukcesu. Quality-Focused Management in Organization - Success Factors, Scientific Papers of Silesian University of TechnologyNo. 128, Organization \& Management/Zeszyty Naukowe Politechniki Śląskiej. Seria Organizacja i Zarzadzanie, pp. 501-516.

\section{Corresponding author}

Marek Bugdol can be contacted at: marek.bugdol@uj.edu.pl

For instructions on how to order reprints of this article, please visit our website:

www.emeraldgrouppublishing.com/licensing/reprints.htm

Or contact us for further details: permissions@emeraldinsight.com 